\title{
Mental health legislation and the care of people with dementia
}

\author{
Margo Wrigley, FRCPI, MRCPsych, Consultant Psychiatrist, Department of Old Age Psychiatry, James Connolly Memorial Hospital, \\ Blanchardstown, Dublin 15, Ireland.
}

The role of mental health legislation in dementia is a controversial subject. However, it is timely to examine this issue as we await a White Paper on mental health legislation in Ireland.

Historically, people with dementia had little support available to them or their carers until institutional care was necessary. Institutional care was then provided in the local psychiatric hospital by default since few other facilities existed. The Person of Unsound Mind committal order of the 1945 Mental Health Act ensured admission to such institutions. This led to the situation whereby all psychiatric hospitals in Ireland had large numbers of people suffering from dementia in long stay wards. With an ageing population, the numbers increased at the expense of the developing acute and community psychiatric services. Planning for the Future tackled the issue but did so by taking an overly narrow view of the role of psychiatry in the care of elderly people with mental illness. Every elderly person was seen as a potential long stay patient so admission became increasingly difficult to achieve. Clearly, this was unsatisfactory.

The development of some specialist Psychiatry of Old Age services in Ireland has to some extent halted this process and led to a re-appraisal of how and when psychiatry can be of benefit to elderly people. New mental health legislation will obviously play an important role in determining how this progresses. It must ensure that elderly people have access to psychiatric services when necessary and that specialist services continue to develop. Certain aspects of the legislation need careful attention to facilitate this.

First and foremost, dementia rather than ambiguous terms such as 'mental infirmity' should be used in any new legislation that is enacted. The main reason that dementia has been difficult to define for mental health legislation purposes is because there is confusion about what aspects of dementia might benefit from psychiatric treatment and what aspects require care in a general sense. The distinction hinges on an understanding of mental competence in the context of dementia. All dementia sufferers except in the earlier phases of the process are mentally incompetent. This means they cannot take responsibility for themselves or their assets. This is a care issue and legally is appropriately dealt with by wardship or where available by an adult care order.

However, if the dementia sufferer has an associated severe behavioural or psychiatric problem psychiatric treatment may be beneficial and, if necessary, should be available on an involuntary basis if clinically indicated. Treatability is the main factor determining whether a committal procedure under mental health legislation is appropriate. A clear understanding of these concepts is essential in ensuring that mental health legislation is used properly for those who suffer from dementia.

Dementia should, therefore, certainly be a reason for admission to psychiatric hospital but only if associated with serious behavioural or psychiatric problems. Careful definition of dementia for the purposes of mental health legislation is essential. It should be precise and, furthermore, the criteria for admission should be the same as for any mental disorder within the remit of the committal section of mental health legislation. The criteria for admission should be either: dangerousness to self or others, or the person's mental state is likely to deteriorate unless he/she receives psychiatric treatment which can only be given in a designated psychiatric centre.

The use of vague phrases such as 'seriously irresponsible behaviour' in any definition of dementia for the purposes of new mental health legislation are far too broad and open to misinterpretation. All dementia sufferers, except in the early stages of the condition, are irresponsible and therefore not mentally competent to care for themselves or their assets as alluded to earlier. The need for care rather than psychiatric treatment would constitute grounds for detention if this ambiguous phraseology is used in the definition of dementia. It would include sufferers with problems such as self-neglect or wandering who are clearly not in need of psychiatric treatment.

Since there are at least 25,000 people suffering from dementia in Ireland the consequences of having such a definition of dementia would be unimaginable for psychiatry and its scarce resources and most inappropriate for those who suffer from dementia.

Another important issue is where people with dementia

Editor-in-Chief: Brian Lawior (Dublin). Editors: Timothy Dinan (London), David King (Belfast). Deputy Editor: Brian O'Shea (Dublin). Associate Editors: Ken Brown (Belfast), Patricia Casey (Dublin), Anthony Clare (Dublin), Stephen Cooper (Belfast), Thomas Fahy (Galway), Michael Fitzgerald (Dublin), Michael Kelleher (Cork), Brian Leonard (Galway), Roy McClelland (Belfast), Aidan McGennis (Dublin), Ciaran O'Boyle (Dublin), Eadbhard O'Callaghan (Dublin), Art O'Connor (Dublin), Ethna O'Gorman (Belfast), Ian Pullen (Edinburgh), David Sheehan (Tampa), Philip Snaith (Leeds), Hugh Staunton (Dublin), John Waddington (Dublin), Richard Williams (Calgary). Statistical Editor: Leslie Daly (Dublin). Deputy Statistical Editor: Ronan Conroy (Dublin). 
who have severe behavioural or psychiatric problems should be treated. Since such patients will generally be treated by specialist Psychiatry of Old Age services to which over half the referrals are of elderly people with functional psychiatric disorders this must be considered carefully.

One possible solution is to have separate functional and dementia wards for elderly people within the psychiatric service. Alternatively, those with functional illness might be managed in a general psychiatry acute ward whilst dementia sufferers are treated in a dementia centre. It very important that elderly people have access to acute psychiatric treatment but especially if very old, they may also have dependency problems and sensory impairments which may not receive due attention in a busy acute general psychiatry ward.

Pragmatically, the best option appears to be a Psychiatry of Old Age Unit catering for both groups of elderly people within the remit of Old Age Psychiatry services either within a designated area in the acute ward or adjacent to it This would ensure that acute psychiatric care together with the necessary attention to the special problems of old age can be provided. Also it is easier for the Psychiatry of Old Age service concerned to manage all its acute patients in one area.

Mental Health Review Boards will undoubtedly be an intrinsic part of any new mental health legislation in Ireland. This is entirely satisfactory and will ensure that people are not inappropriately detained in psychiatric hospitals and that they have a means of seeking a review of their detention if they so wish.

However, the issues surrounding people with dementia who are detained on an involuntary basis in a psychiatric hospital are very different to the generality of patients with psychiatric problems. For this reason it is important that the psychiatrists on the Review Board include specialists in the Psychiatry of Old Age who would be able to advise on elderly people with dementia who are detained.

Care rather than psychiatric treatment of dementia sufferers should be provided for in legislation. There is a question as to whether it should be under Mental Health Legislation or in general legislation applying to elderly people specifically. Such legislation is used to protect elderly people, who are abused, exploited or are seriously neglecting themselves. This sort of behaviour is not confined to elderly people with dementia and may occur in those with normal mental function. If the legislation was included in mental health legislation a number of problems would occur. First, abused, neglected or exploited elderly people with normal mental function could not be protected since a diagnosis of mental disorder would be necessary to make a Care Order. This would be a major short-coming since there is much evidence showing abuse of elderly people is widespread and not confined to those with dementia. Second, psychiatrists would probably play a key role in initiating such orders and, if so, would be expected to provide whatever services and facilities are required by the person on the order.

In most instances this will involve moving the person into residential care. Since psychiatrists in general only have access to psychiatric facilities, people would again be admitted to psychiatric hospitals for general care rather than psychiatric care and treatment. This would be inappropriate for the people concerned and equally would divert psychiatric resources causing immense problems for these services.

However, if the Care Order for elderly people was in general legislation all vulnerable elderly could be protected. Furthermore such people could be moved to a residential setting suited to their assessed needs. The Place Of Safety Order for abused children provides a good model for a care order for elderly people. In this model the Director of Community Care applies to the court for an order having collected evidence of abuse, neglect or exploitation. A psychiatrist or geriatrician might be called to give an opinion to the court in conjunction with the evidence and if satisfied the court would make a care order. There should be an onus on the health board concerned to provide a suitable place of safety for the elderly person.

Another aspect of current legislation which would benefit from modification is that wards of court might be more easily transferred to a psychiatric centre if such treatment is clinically indicated. The present arrangement is that permission has to be sought from the High Court and this can delay treatment unnecessarily. The Registrar of the Wards of Court Office should, of course, always be informed of such a transfer. Generally, wardship proceedings are extremely useful for elderly people who suffer from dementia and who have substantial assets because taking the person into wardship provides both for the care of the person and their assets and does so in a way that safeguards the person very securely.

In summary, mental health legislation is required for those who suffer from dementia to ensure that they receive psychiatric treatment when necessary. However, the legislation should be based on the need for treatment rather than the need for care and crucial to this is an understanding of the concept of mental competence in those who suffer from dementia. Many of the misunderstandings of the past have arisen from the lack of adequate resources, particularly residential care for people with dementia. Hand in hand with the enactment of appropriate legislation should be the development of appropriate facilities for such people.

Original manuscript received December 10,1994

Final revision accepted February 17, 1995. 